\title{
PROXIMAL HUMERUS FRACTURE WITH LOCKING PLATE: FUNCTIONAL AND RADIOGRAPHIC RESULTS
}

\section{FRATURAS DO ÚMERO PROXIMAL COM PLACA BLOQUEADA: RESULTADOS FUNCIONAIS E RADIOGRÁFICOS}

\author{
Rodrigo Souto Borges Petros ${ }^{1}$, fabiano Rebouças Ribeiro ${ }^{1}$, antonio Carlos tenor Junior ${ }^{1}$, Rômulo Brasil Filho ${ }^{1}$, \\ CANTÍDIO SALVADOR FILARDI JUNIOR ${ }^{1}$, Danilo CANESIN DaL MOLIN ${ }^{1}$
}

1. Shoulder and Elbow Group, Orthopedics and Traumatology Service, Hospital do Servidor Público Estadual de São Paulo (SOT/HSPE), São Paulo, SP, Brazil.

\section{ABSTRACT}

Objective: To correlate the functional outcome and radiographic indices of proximal humerus fractures treated with locking plate. Methods: Seventy patients with proximal humerus fractures treated with locking plate, with mean follow-up of 30 months. These patients were analyzed for the score of the University of California, Los Angeles (UCLA) for the operated shoulder, range of motion measurements and radiography of both shoulders. After that, a graphical correlation was established between the radiographic measurements and the functional outcomes. Results: $78 \%$ good and excellent results according to the UCLA score, with mean $130^{\circ}$ elevation; $45^{\circ}$ lateral rotation; and thumb-T10 medial rotation. The type of fracture according to the Neer classification and age had a significant correlation with the range of motion. An association was found between the lowest mean elevation and the UCLA score when the neck-shaft angle variation in the antero-posterior plane was greater than $15^{\circ}$ varus $(p<0.001)$. Conclusion: The variation of the neck-shaft angle measurement in the anteroposterior plane showed significant correlation with the range of motion and can be one of the predictors of functional results in proximal humerus fractures treated with locking plate. Level of evidence III, Retrospective Study.

Keywords: Humeral fractures/surgery; Fracture fixation, Internal; Humeral fractures/radiographic evaluation.

\section{RESUMO}

Objetivo: Correlacionar os resultados funcionais e os índices radiográficos das fraturas do úmero proximal tratadas com placa bloqueada. Métodos: Examinou-se 70 pacientes com fraturas do úmero proximal tratados com placa bloqueada, com seguimento médio de 30 meses. Esses pacientes foram submetidos à análise do escore da Universidade da Califórnia de Los Angeles (UCLA) no ombro operado, avaliação do arco de movimento e a exames radiográficos de ambos os ombros. Estabeleceu-se, então, a correlação gráfica entre as medidas radiográficas e os resultados funcionais. Resultados: Obtivemos 78\% de bons e excelentes resultados conforme o escore da UCLA, com médias de: $130^{\circ}$ de elevação; $45^{\circ}$ de rotação lateral; e polegar-T10 de rotação medial. O tipo de fratura segundo a classificação de Neer e a idade teve significativa correlação com o arco de movimento. Encontrou-se associação entre menor média de elevação e escore UCLA quando a variação do ângulo cervicodiafisário na incidência anteroposterior foi maior que $15^{\circ} \mathrm{em}$ varo $(p<0,001)$. Conclusão: A variação da medida do ângulo cervicodiafisário na incidência anteroposterior mostrou significativa correlação com o arco de movimento, podendo ser um dos preditores dos resultados funcionais nas fraturas do úmero proximal tratadas com placa bloqueada. Nível de Evidência III, Estudo Retrospectivo.

Descritores: Fraturas do úmero/cirurgia; Fixação interna de fraturas; Fraturas do úmero/avaliação radiográfica.

Citation: Petros RSB, Ribeiro FR, Tenor Jr AC, Brasil Filho R, Filardi Jr CS, Dal Molin DC. Proximal humerus fracture with lock plate: functional and radiographic results. Acta Ortop Bras. [online]. 2019;27(3):164-8. Available from URL: http://www.scielo.br/aob.

\section{INTRODUCTION}

Proximal humeral fractures are relatively frequent; they account for $5-10 \%$ of all fractures. ${ }^{1}$ Their incidence is 6.6 cases for every 1000 people every years ${ }^{2}, 70 \%$ in patients above 60 years old. They are the second most common upper limb frac-ture and the third most common in patients above 75 years old. The most common mechanism of injury is fall from stand-ing protected by the extended hand. ${ }^{3}$
Approximately $80 \%$ of these fractures have no displacement or are minimally displaced and sta-ble, resulting from low-energy trauma, and can be treated non-surgically ${ }^{4}$ with good prognosis. Surgical treatment is reserved for patients with fractures that are displaced, unsta-ble, open, associated to vascular injury, or in polytrauma patients.

According to the literature, there is no unique treatment method that is effective for all types of proximal humeral fractures. The

All authors declare no potential conflict of interest related to this article.

This study was conducted at the Orthopedic and Trauma Service, Hospital do Servidor Público Estadual de São Paulo (SOT/HSPE), São Paulo, SP, Brazil. Correspondence: Rodrigo Petros, Avenida Lucio Costa 4000 bl: 08/302, Barra da Tijuca. Rio de Janeiro, RJ, 22630-011, Brazil. rodpetros@yahoo.com.br 
most commonly used surgical techniques are: closed reduction and fixation with pins or percuta-neous screws, open reduction and internal fixation with plate and screws or with tension band, intramedullary nails, and hemiarthroplasty. ${ }^{1,5}$

Internal fixation of the proximal humerus with locking anatomic plate favors the maintenance of the reduction obtained during surgery, allowing for earlier passive mobiliza-tion and thus facilitating post-operative rehabilitation. ${ }^{6}$

However, this technique is not free from complication. The most common among them are: limitation of range of movement, avascular necrosis, loosening of the synthesis material, articular penetration of screws, and/or varus fixation of the humeral head. ${ }^{7}$

This study aimed to evaluate the correlation between functional outcomes and radiographic indices of proximal humeral fractures treated with locking anatomical plate.

\section{METHODS}

This was a retrospective study conducted by the Shoulder and Elbow Group of the Orthopedics and Traumatology Service of the hospital, from february 2006 to May 2010, with 143 patients who suffered fracture of the proximal humerus and under-went surgical treatment (open reduction and internal fixation) with locking anatomic plate (PHILOS - Synthes ${ }^{\circledR}$ ).

The following patients were excluded: 5 patients with bilateral fractures; 6 individual for pre-senting infection (re-operated for removal of the synthesis material); 4 in which loss of fixation were replaced by hemiarthroplasty and 58 due to loss of follow-up.

Of the 70 patients available for study, 44 fractured the right side and 26 on left side; 41 the dominant side and 29 the non-dominant; 50 were female and 20 male. The average age of patients was 67 years ranging from 21 to 92 years and the mean follow-up time was 30 months, ranging from 13 to 64 months. The most common mechanism of injury was fall from standing in $72 \%$ of de cases (Table 1 ).

The classification used in this study was described by $\mathrm{Neer}^{8}$ in 1970, based on displacement of the four main frag-ments, which were firstly identified by Codman in 1934" humeral head, greater tuberosity, lesser tuberosity, and diaphysis. According to Neer, ${ }^{8}$ multiple parts are considered when there are deviations greater than $1 \mathrm{~cm}$ or $45^{\circ}$ between frag-ments. For the greater tuberosity, a distance greater than $5 \mathrm{~mm}$ makes it a displaced part.

\begin{tabular}{c|c} 
Table 1. Epidemiology. & \\
\hline Genre & 20 \\
\hline Male & 50 \\
\hline Female & \\
\hline Member & 44 \\
\hline Right & 26 \\
\hline Left & $41(59 \%)$ \\
\hline Affected dominant side & $30(18-64)$ months \\
\hline Mean follow-up & $67(21-92)$ year \\
\hline Average age & \\
\hline Trauma mechanism & $49(72 \%)$ \\
\hline Fall from standing & $6(8 \%)$ \\
\hline Running over & $6(8 \%)$ \\
\hline Motorcycle accident & $6(8 \%)$ \\
\hline Car accident & $3(4 \%)$ \\
\hline Drop in height & $20(29 \%)$ \\
\hline Neer classification & $37(53 \%)$ \\
\hline 2 part & $13(18 \%)$ \\
\hline 3 part &
\end{tabular}

For diagnosis and preoperative classification, $X$-rays in the true shoulder anteroposterior, scapular $Y$, and Velpeau views were used, as well as CT scan when there was doubt regarding articular involvement. Of the 70 studied fractures, 20 were classified as two-part, 37 as three-part, and 13 as four-part.

To assess the functional results, patients with a minimum of 12 months of follow-up were included. The degree of flexion and rotation (lateral and medial) of both shoulders was measured and the University of California in Los Angeles (UCLA) score was applied.

Postoperative radiographic evaluation was standardized with a $100 \mathrm{~cm}$ distance from the X-ray apparatus to the film in the anteroposterior incidence (AP), with correction of anteversion of the glenoid cavity and limb in neutral rotation; scapular $Y$ made with the patient standing in the posteroanterior posi-tion with $45^{\circ}$ anteriorly and the X-ray apparatus toward the scapula; and Velpeau view a modification of axillary profile for patients with upper limb immobilization. Radiographs were always made on the same day by the same previously trained staff, at least 18 months after surgery.

The radiographic measurements assessed were the cervicodiaphyseal angle (formed by the intersection between a line perpendicular to the anatomical neck and a line parallel to the axis of the humeral diaphysis), compared to the non-operated side in true shoulder anteroposterior view ${ }^{1}$ (Figure 1), and scapular $Y$ (angle between a line passing through the anatomical neck and a line parallel to the diaphysis of proximal humerus (Figure 2), and distance between the proximal end of the plate and the apex of the greater tuberosity on the true shoulder anteroposterior view. The presence of pseudoarthrosis, avascular necrosis, and osteolysis was investigated.

Subsequently, the correlation between changes in radio-graphic measurements and functional results was calculated.

In the statistical analysis, the relationship between quantitative variables was chosen by Spearman's correlation. In studies of the variations we used the Kolmogorov-Smirnov test Lilliefors correction to verify the normality of the data. If it were not rejected the normality of the data was used the Student t test.

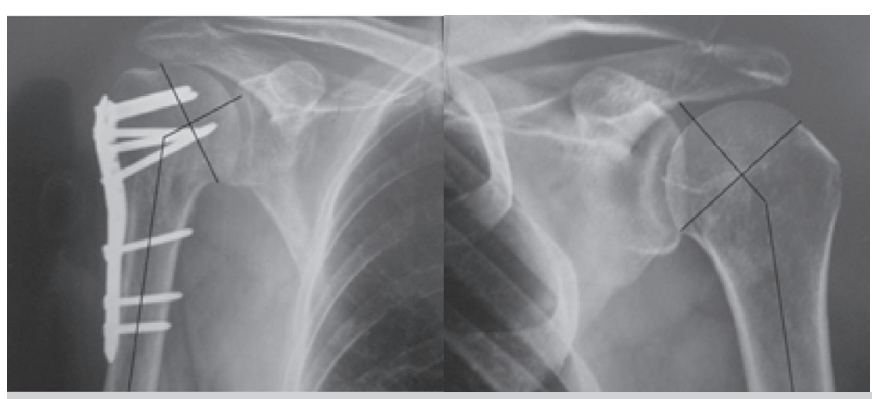

Figure 1. Measurement of cervicodiaphyseal angle in the anteroposterior incidence of both shoulders.

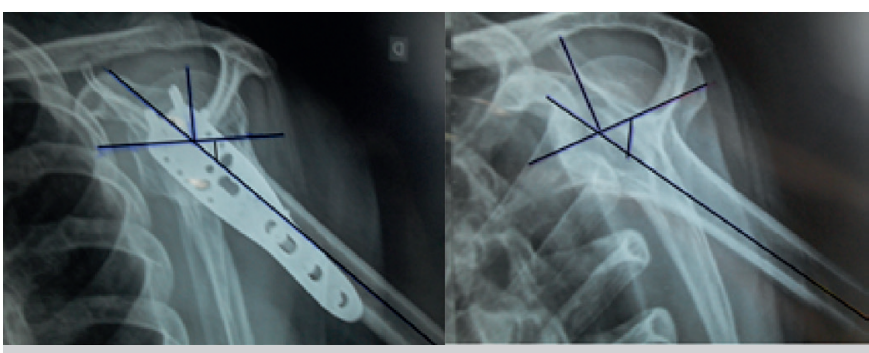

Figure 2. Measure the angle in the scapular $Y$ incidence of the both shoulders 


\section{RESULTS}

\section{Functional results}

For the 70 patients analyzed, the mean elevation of the operated limb was $130^{\circ}\left(30^{\circ}-170^{\circ}\right)$, with a loss of $21 \%$ compared to the contralateral side $\left(164^{\circ}\right)$, the mean of external rotation (ER) was $45^{\circ}$ with $30 \%$ reduction compared to the opposite side $\left(64^{\circ}\right)$ and the mean of internal rotation (IR) was thumb-T10, with its contralateral side mean was thumb-T7.

In the UCLA score, we obtained 51 patients with excellent and good results (72.9\%), 12 regular (17.1\%) and 7 with poor results $(10.0 \%)$. Of these, 67 had to be satisfied (95.7\%) and 3 unsatisfied (4.3\%). In 37 patients had three-parts fractures, 29 presented excellent and good results (78.38\%), six patients was regular results (16.22\%) and two with poor results (5.40\%). The mean of range of motion losses compared to the contralateral side were: $31^{\circ}$ elevation $\left(163^{\circ}-132^{\circ}\right), 20^{\circ}$ external rotation $\left(64^{\circ}-44^{\circ}\right)$ and three internal rotation vertebrae (T7-T10). The worst scores of the study were in fractures classified as four-parts, four cases with excellent and good results $(30.77 \%)$, four regular (30.77\%) and five with poor results (38.46\%).In the assessment of range of motion, the mean for elevation was $89^{\circ}$ with a decrease of $45 \%$ compared to contralateral shoulder $\left(162^{\circ}\right)$. The external rotation loss was $28^{\circ}$ with $45 \%$ reduction of motion $\left(60^{\circ}-32^{\circ}\right)$. The average internal rotation-L1 was thumb with opposite side thumb-T9 (Table 2).

Results statistically significant $(p<0.05)$ when comparing the UCLA score and elevation, with age and number of parts of the Neer classification. The higher the age and the number of parts, the worst the flexion and UCLA score.(Figure 3 and 4).

\section{Radiographic evaluation}

In radiographic evaluation, five (7.14\%) patients had avascular necrosis is therefore not possible to estimate the pre-established measures for the study (all classified as Neer fractures in 4 parts preoperatively).

Of the 65 patients studied, the mean of cervicodiaphyseal the anteroposterior was: $131^{\circ}$ on the operated side $\left(82^{\circ}-210^{\circ}\right)$ and $138^{\circ}$

Table 2. The mean of range of motion the operated side (OS) ,the contralateral shoulder (CL) and UCLA score.

\begin{tabular}{c|c|c|c|c|c|c|c}
\hline $\begin{array}{c}\text { Neer } \\
\text { classification }\end{array}$ & $\begin{array}{c}\text { Elevation } \\
\text { OS }\end{array}$ & $\begin{array}{c}\text { Elevatinon } \\
\text { CL }\end{array}$ & RE OS & RE CL & RI OS & RI CL & $\begin{array}{c}\text { UCLA } \\
\text { Mean }\end{array}$ \\
\hline 2 part (20 patients) & $152^{\circ}$ & $163^{\circ}$ & $51^{\circ}$ & $62^{\circ}$ & T8 & T7 & 32.65 \\
\hline 3 part (37 patients) & $132^{\circ}$ & $163^{\circ}$ & $44^{\circ}$ & $64^{\circ}$ & T10 & T7 & 31.10 \\
\hline 4 part (13 patients) & $89^{\circ}$ & $162^{\circ}$ & $32^{\circ}$ & $60^{\circ}$ & L1 & T8 & 22.84 \\
\hline
\end{tabular}

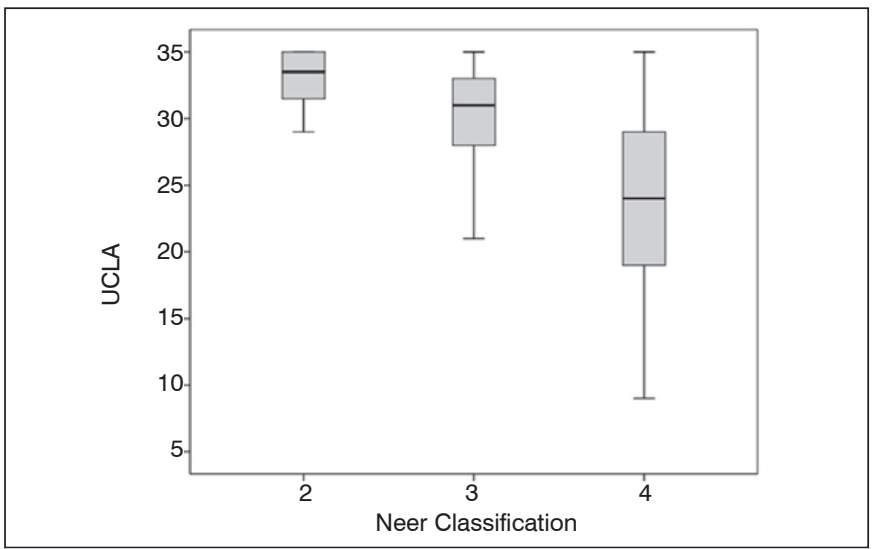

Figure 3. Relationship between Neer classification UCLA score $(p<0.0001)$. the contralateral shoulder $\left(126^{\circ}-152^{\circ}\right)$, the mean in the scapular $Y$ view was $60^{\circ}$, and opposite side measuring $57^{\circ}$. The greatest differences were observed in four-parts fractures, specifically in the anteroposterior view that showed a difference of $17^{\circ}$ compared to non-operated side (Figure 5).

When measuring the distance between the proximal end of the plate and the apex of the greater tuberosity, a mean of $6 \mathrm{~mm}$ (range: 0-1.6 mm) was obtained and in two cases is greater tuberosity of osteolysis.

\section{Correlation between radiographic and functional outcomes}

The worst functional outcomes were observed in cases where the difference between the operated and contralateral side was greater than or equal to $15^{\circ}$ varus in the anteroposte-rior incidence. In such cases, the patients had lower mean flexion $\left(105,40^{\circ}\right)$ and worse UCLA score $(26,40)$. Patients who had variations lower than $15^{\circ}$ had mean flexion of $151^{\circ}$ and mean UCLA score of 32,85. These results were statistically significant in the present study. (Figure 6) (Table 3)

For analysis of the distance between the proximal end of the plate and the apex of the greater tuberosity, patients were divided into two groups: the first, with values lower than $8 \mathrm{~mm}$, and the second, with values greater than or equal to $8 \mathrm{~mm}$. By comparing the results of bending between the two groups was not statistically significant (Table 4).

We did not obtain statistically significant results, to correlate the radiographic measurements for scapular $Y$ view with functional outcomes and UCLA.

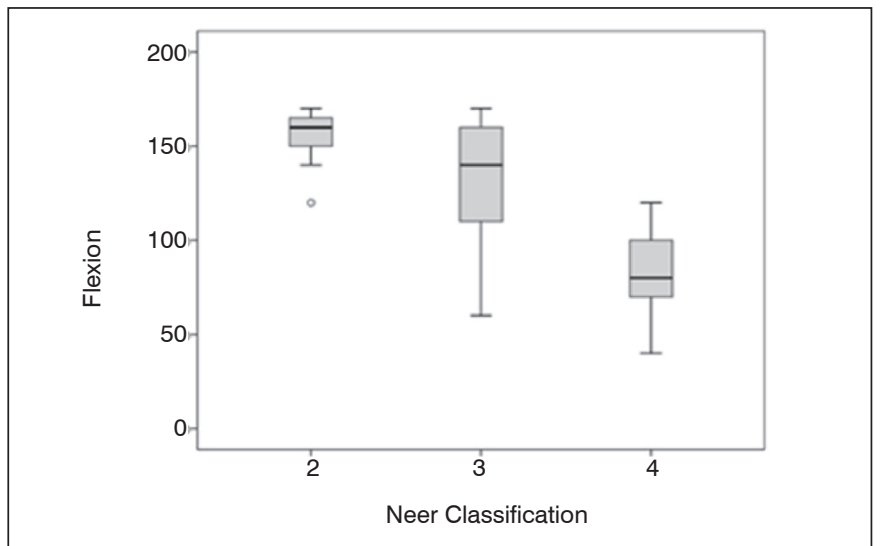

Figure 4. Relationship between Neer classification with flexion $(p<0.0001)$.

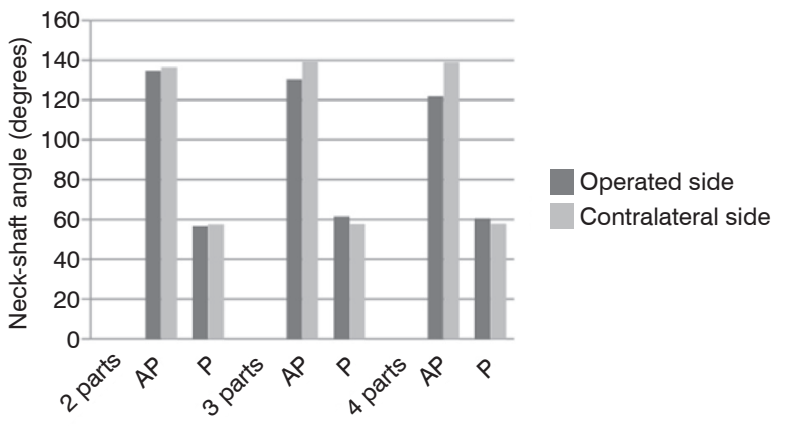

Figure 5. Cervicodiaphyseal in the anteroposterior (AP); and scapula profile $(P)$ 


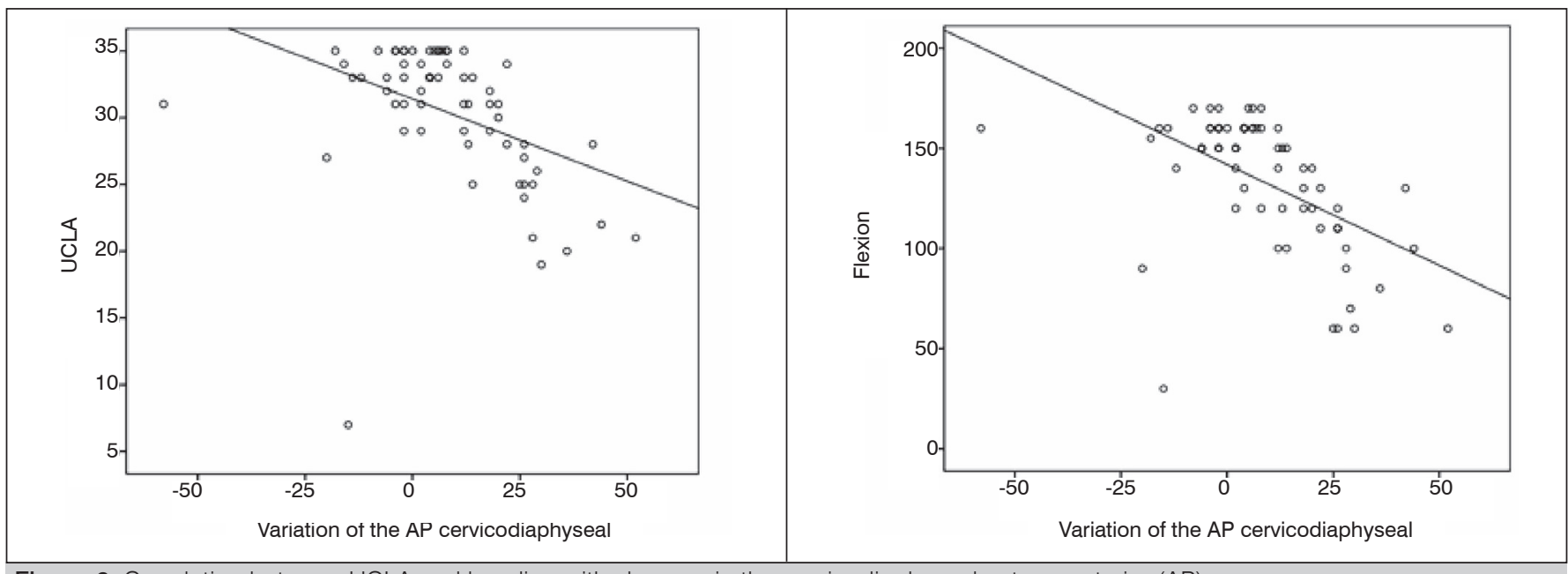

Figure 6. Correlation between UCLA and bending with changes in the cervicodiaphyseal anteroposterior (AP).

Table 3. Correlation between the variation in cervicodiaphyseal anteroposterior with UCLA and elevation $(p<0.001)$ (SD = standard deviation).

\begin{tabular}{c|c|c|c|c|c|c}
\hline \multirow{2}{*}{} & \multicolumn{5}{|c}{ Variation of the angle cervicodiaphyseal } \\
\cline { 2 - 7 } & \multicolumn{3}{|c|}{$<15$} & \multicolumn{3}{c}{$>=15$} \\
\cline { 2 - 7 } & Mean & Median & DP & Mean & & DP \\
\hline UCLA & 32.85 & 33.00 & 2,359 & 26.40 & & 6,035 \\
\hline Elevation & 151.00 & 160.00 & 17.802 & 105.40 & M & 35.176 \\
\hline
\end{tabular}

Table 4. Correlation between the elevation and the distance of the end of the plate relative to the apex of the greater tuberosity (TMP).

\begin{tabular}{c|c|c|c|c|c|c|c}
\hline & \multicolumn{6}{|c|}{ TMP } & p-value \\
\cline { 2 - 8 } & \multicolumn{3}{|c|}{$<\mathbf{0 . 8}$} & \multicolumn{3}{c|}{$\mathbf{0 . 8}$} & \\
\cline { 2 - 8 } & Mean & Median & DP & Mean & Median & DP & \\
\hline Elevation & 133.46 & 140 & 30.718 & 134.4 & 150 & 39.59 & .5531 \\
\hline
\end{tabular}

\section{DISCUSSION}

In the present study, it was observed that deviations greater than $15^{\circ}$ varus relative to contralateral shoulder in anteropos-terior view are not well tolerated by the patient and lead to with flexion loss and a worse UCLA score.

Solberg et al ${ }^{10,11}$ reached a similar conclusion. In their study, the authors divided the results according to the obtained alignment relative to the contralateral shoulder. They considered less than $5^{\circ}$ of varus angulation of the humeral head as a good reduction. In turn, a satisfactory reduction ranged from $5^{\circ}$ and $20^{\circ}$ of varus deformity of the humeral head. The authors concluded that patients with good or satisfactory reductions had better outcomes than patients with varus deformity greater than $20^{\circ}$, who presented flexion loss and worse functional outcome.

Herbert Resch, ${ }^{12}$ in a 2011 review article, also considered these parameters to be important, and proposed a classification based on varus and valgus deviations. Brunner et $\mathrm{al}^{13}$ observed inferior results when the reduction of the fracture had cervicodiaphyseal angle with an increased varus; how-ever, their results were not statistically significant.

Although the surgical technique recommend that the distance of the plate relative to the greater tuberosity should be $8 \mathrm{~mm}$ and lower distances lead to a deficit of abduction and flexion due to impact of the plate on the acromion ${ }^{14}$, in our study we showed no difference statistically significant difference between the groups with plate $<8 \mathrm{~mm}$ plate compared with $\geq 8 \mathrm{~mm}$ below the apex of the greater tuberosity. In the functional evaluation, three patients were not satisfied with the treatment, according to the UCLA score, seven patients were considered poor results. Five cases were fractures in four parts and evolved into avascular necrosis (7,14\%). Brunner et al ${ }^{13}$ reported a number, with $8 \%$ necrosis in a multicenter study of 158 fractures. Patients with avascular necrosis present the worst functional results. However, elderly patients, who have lower functional demand, tolerate this complication better. ${ }^{15}$

The $72,9 \%$ excellent and good results observed in the present study are accordance levels reported in the literature. In 2011, Hirschmann et $a{ }^{16}$ published a study with 64 patients with a minimum follow-up of four years, treated with locking plate, and reported $75 \%$ excellent and good results. They also concluded that these results continued to improve even one year after the surgery. Rose et $\mathrm{al}^{17}$ found $75 \%$ consolidation and excellent results.

In the present study, the higher the age of the patient and the number of parts of the fracture, the worst the flexion and the UCLA score. These results were statistically significant $(p<0.003)$. Yang et $a^{18}$ found that the higher number of fracture parts and the lack of medial support (calcar comminution) were determiners of the functional outcome. Koukakis et $\mathrm{al}^{19}$ also had worse outcomes related to age. In the present study, the cervicodiaphyseal angle was used as a comparative radiographic parameter with the contralateral shoulder for correlation with functional outcomes. However, there is no universal standardized method to measure this angle.

Other biases in the results of this study which were not analyzed are the co-morbidities of patients, prior and late postoperative integrity of the rotator cuff, the extremes of the age. Further studies with greater emphasis on such factors are needed to complement the present findings.

\section{CONCLUSION}

This study indicates that the variation of the cervicodiaphyseal angle in the anteroposterior view was significant correlation with the range of motion. This radiographic parameter can be one of the predictors of functional results in fractures of the proximal humerus treated with locking plates. 


\section{REFERENCES}

1. Lanting B MacDermid J Drosdowech D, Faber KJ. Proximal humerus fractures: a systematic review of treatment modalities. J Shoulder Elbow Surg. 2008; 17 (1): 42-54.

2. N Südkamp, Bayer J, Hepp P, Voigt C, H Oestern, Kaab MEt el. Open reduction and internal fixation of proximal humeral fractures with use of the proximal humerus locking plate. Results of a prospective, multicenter, observational study. J Bone Joint Surg Am 2009; 91 (6): 1320-8.

3. Thanasas $C$ Kontakis G Angoules A Limb D Giannoudis P. Treatment of proximal humerus fractures with locking plates: a systematic review. J Shoulder Elbow Surg. 2009; 18 (6): 837-44.

4. Egol KA, Ong CC, Walsh M, Jazrawi LM, Tejwani NC, Zuckerman JD.. Early complications in proximal humerus fractures (OTA Types 11) treated with locked plates. J Orthop Trauma. 2008 Mar;22(3):159-64.

5. Monteiro GC, Ejnisman B, CV Andreoli, Pochini AC, Olympio E. Results of the third fracture of treatment of proximal humerus with lock plates, Acta Ortop Bras. 2011; 19 (2): 69-73.

6. Hirschmann MT,Quarz V,Audigé L,Ludin D,Messmer P,Regazzoni P,et al. Internal Fixation of Unstable Proximal Humerus Fractures With an Anatomically preshaped Interlocking Plate: Clinical and Radiologic Evaluation. J Trauma. 2007; 63 (6): 1314-1323.

7. Owsley KC, Gorczyca JT. Fracture displacement screw cutout and after reduction and locked open plate fixation of proximal humeral fractures. J Bone Joint Surg Am 2008; 90 (2):. 233-40.

8. Neer CS 2nd. Displaced proximal humeral fractures. Classification and evaluation. J Bone Joint Surg Am 1970.; 52 (6): 1077-89.

9. Codman EA. Fractures in relation to the subacromial bursa. In Codman EA, editor. The shoulder. Rupture of the supraspinatus tendon and other lesions in or about the subacromial bursa. Boston: Thomas Todd; 1934. p. 313-33.

10. Solberg BD, Moon CN, Franco DP, Paiement GD. Surgical Treatment of Three and Four-Part Proximal Humeral Fractures. J Bone Joint Surg Am. 2009; 91 (7): 1689-97.

11. Solberg BD, Moon CN, Franco DP, Paiement GD. Locked plating of 3- and 4-part proximal humerus fractures in older Patients: The effect of initial fracture pattern on outcome. J Orthop Trauma. 2009 Feb; 23 (2): 113-9.

12. H Resch. Proximal humeral fractures: current controversies. J Shoulder Elbow Surg. 2011; 20 (5): 827-32

13. Brunner F, Sommer C, Bahrs C, Heuwinkel R, Hafner C, Rillmann PEt el. Open reduction and internal fixation of proximal humerus fractures using locked proximal humeral plate: a prospective multicenter analysis. J Orthop Trauma. 2009; 23 (3): 163-72.

14. S Sinha, CP Kelly, Ali Narvani, and Ofer Levy. Fixation of fractures of the proximal humerus. Ann R Coll Surg Engl. 2010 Nov; 92(8): 631-638.

15. AJ, Roolker W, Patt TW, EL Raaymakers, Marti RK. Open reduction and internal fixation of three and four-part fractures of the proximal part of the humerus. $J$ Bone Joint Surg Am 2002; 84 (11): 1919-1926.

16. Hirschmann MT, B Fallegger, Amsler F, Regazzoni P, Gross T. Longer-Term Clinical Results After Internal Fixation of the Proximal Humerus Fractures With Locking compression plate (PHILOS). J Orthop Trauma 2011; 25 (5): 286-293.

17. Rose PS, Adams CR, Torchia ME, Jacofsky DJ, Haidukewych GG, Steinmann SP. Locking plate fixation for proximal humeral fractures: initial results with a new implant. J Shoulder Elbow Surg. 2007; 16 (2): 202-7.

18. Yang H, Li Z, Zhou F, Wang D, Zhong B. A prospective clinical study of proximal humerus fractures treated with proximal humerus locking plate. J Orthop Trauma. 2011; 25 (1): 11-7.

19. The Koukakis, Apostolou CD, Taneja T, Korres DS, The Amini. Fixation of proximal humerus fractures using the plate PHILOS: early experience. Clin Orthop Relat Res 2006; 442:. 115-120. 